\title{
Relações sociais, pandemia da covid-19 e ensino médio
}

\author{
Sáhira Michele da Silva Celestino (D) https://orcid.org/0000-0001-6343-6889 \\ Rita de Cássia de Souza (10) http://orcid.org/0000-0001-9823-6174 \\ ${ }^{1}$ Universidade Federal de Viçosa (UFV), Brasil
}

Resumo. A pandemia da covid-19 acarretou mudanças na maneira de agir das pessoas, impactando a economia, política, saúde e educação. Diante deste contexto, este artigo traz parte de uma pesquisa realizada com alunos, professores e funcionários de uma escola do Ensino Médio da Rede Estadual de Ensino em Cajuri-MG. O público pesquisado foi de 56 participantes: 44 alunos do ensino médio, 7 docentes e 5 funcionários da escola investigada. Todos os participantes responderam a um questionário elaborado pela pesquisadora. Os professores responderam a um questionário com 4 questões abertas e 36 fechadas com escala Likert. O questionário entregue aos discentes continha um total de 41 perguntas - 37 fechadas e 4 abertas. E o questionário dos funcionários continha 31 questões fechadas e 4 abertas. Diante dos resultados, nesse contexto de pandemia, os participantes da pesquisa passaram a valorizar e compreender a importâncias das relações, sobretudo na escola. Os estudantes abordaram a falta de interação com os colegas e professores; os docentes e funcionários também falaram sobre a falta dos alunos. A instituição escolar adotou o ensino remoto que, na visão dos educadores e estudantes, consideravam que o aprendizado tinha sido prejudicado com essa metodologia.

Palavras-chave: construcionismo social; ensino médio; pandemia, relações sociais

Relaciones sociales, pandemia de la covid-19 y la enseñanza secundaria

Resumen. La pandemia del covid-19 supuso cambios en la manera de actuar de las personas, impactando la economía, la política, la salud y la educación. Ante este contexto, este artículo trae parte de una investigación realizada con alumnos, profesores y funcionarios de una escuela de Enseñanza Secundaria de la Rede Estadual de Ensino de Cajuri-MG. Un total de 56 personas participaron de la encuesta: 44 alumnos de la enseñanza secundaria, 7 docentes y 5 funcionarios de la escuela. Todos los participantes contestaron a un cuestionario elaborado por la investigadora. Los profesores contestaron a un cuestionario con 4 preguntas abiertas y 36 cerradas con escala Likert. El cuestionario entregado a los alumnos era compuesto por un total de 41 preguntas - 37 cerradas y 4 abiertas. Y el cuestionario de los funcionarios comprendía 31 preguntas cerradas y 4 abiertas. Ante los resultados, en ese contexto de pandemia, los participantes de la investigación pasaron a valorar y a comprender la importancia de las relaciones, sobre todo en la escuela. Los estudiantes citaron la falta de interacción con los colegas y profesores; los docentes y funcionarios también hablaron sobre la falta de alumnos. El centro escolar adoptó la enseñanza remota que, según la visión de los educadores y estudiantes, consideraban que el aprendizaje había sido perjudicado con esa metodología.

Palabras clave: construccionismo social; enseñanza secundaria; pandemia, relaciones sociales.

Social relations, covid-19 pandemic and high school

Abstract. The covid-19 pandemic caused changes in the way people act, impacting the economy, politics, health, and education. In this context, this article is part of a research carried out with students, teachers and employees of a high school inserted into the State Education System in Cajuri, Minas Gerais State. The public surveyed was composed by 56 participants: 44 high school students, 7 teachers and 5 employees of the investigated school. All participants answered a questionnaire prepared by the researcher. The teachers answered a questionnaire with 4 discursive and 36 multiple choice questions using the Likert scale. The questionnaire delivered to the students contained a total of 41 questions - 37 multiple choice and 4 discursive questions. And the employee questionnaire contained 31 multiple choice and 4 discursive questions. Given the results, in this pandemic context, the research participants began to value and understand the importance of relationships, especially at school. The students addressed the lack of interaction with colleagues and teachers; teachers and staff also spoke about the absence of students. The school institution adopted remote teaching, which, according to both educators and students, considered that learning had been impaired with this methodology.

Keywords: social constructionism; high school; pandemic; social relations. 


\section{Introdução}

O clima social escolar consiste em como as pessoas se sentem dentro da escola. Está diretamente ligado às relações entre os professores, a gestão, os alunos, a família/ comunidade, bem como as atividades de ensino-aprendizagem, seja dentro de sala de aula, seja no recreio, em relação ao horário das aulas, aos conteúdos escolares, às regras pedagógicas, avaliações, etc. e interfere no processo de ensino-aprendizagem e na qualidade de vida das pessoas envolvidas no ambiente escolar. O clima social pode ser afetado de acordo com o contexto em que a instituição está inserida.

O mundo mudou rapidamente com a pandemia da covid-19로 , covid 19 e, para Marcia Gorett Grossi, Dalva Minoda e Renata Fonseca (2020) as transformações perpassam a economia, política, relações sociais, cultura, psicologia social, relação com a cidade e com o espaço público e também a educação se insere neste contexto sofrendo modificações. De acordo com as autoras, em 2020, mais de 1,5 bilhão de estudantes de 165 países foram afetados pelo fechamento das escolas por causa do coronavírus (medida tomada para frear a proliferação do vírus).

Com o intuito de amenizar as consequências da pandemia, vários estados brasileiros como São Paulo, Rio de Janeiro, Espírito Santo, entre outros, aderiram ao período remoto (mediado por tecnologias digitais da informação e da comunicação) para que os estudantes não ficassem afastados do processo de ensino-aprendizagem. Assim, o estado de Minas Gerais adotou essa metodologia, porém houve diversas implicações neste novo modelo adotado como, por exemplo, a dificuldade de alunos e professores de acessarem a internet e a falta de aparelhos adequados para o acompanhamento das aulas.

Iniciamos nosso estudo no Mestrado em Educação nos anos de 2019 e 2020 buscando entender a afetividade na escola e o quanto esta afeta as relações escolares e aprendizagem. Baseadas na perspectiva construcionista social, entendemos que o ser humano e tudo que se refere a ele é relacional. Assim, de acordo com Gergen e Gergen (2010), nossos estados emocionais não são individuais, e sim construídos coletivamente. Nesta perspectiva, buscamos uma maneira de estudar como se dão estas vivências afetivas na escola, considerando-as como algo relacional e, para isso, optamos por utilizar o conceito de clima social escolar. Nossa pesquisa foi realizada durante o contexto pandêmico, sendo assim, pesquisamos como os participantes se sentiam neste período. Nesse sentido, surge a questão norteadora deste artigo: Qual o impacto da pandemia nas relações escolares? Para responder este questionamento, realizamos um estudo com o objetivo de apresentar os impactos da pandemia do Covid-19 na educação sob a perspectiva dos alunos, professores e funcionários do Ensino Médio da Rede Estadual de Ensino em Cajuri-MG.

Nesta instituição, as aulas foram suspensas no mês de março de 2020, por tempo indeterminado e a Secretaria de Estado de Educação de Minas Gerais (SEE/ MG) elaborou o Regime de Estudo Não Presencial. Para tanto, foi ofertado aos estu-

\footnotetext{
${ }^{1}$ A covid-19 é uma doença causada pelo coronavírus, denominado SARS-CoV-2, que apresenta um espectro clínico variando de infecções assintomáticas a quadros graves. Em dezembro de 2019, houve a transmissão de um novo coronavírus (SARS-CoV-2), o qual foi identificado em Wuhan na China e causou a covid-19, sendo em seguida disseminada e transmitida pessoa a pessoa. A doença foi disseminada mundialmente, por isso o uso do termo pandemia. Disponível em https://coronavirus.saude.gov.br/sobre-a-doenca
} 
dantes um Plano de Estudos Tutorado (PET)2, organizado de acordo com o Currículo Referência de Minas Gerais3 e com o Plano de Curso da unidade de ensino4 com atividades não presenciais que os alunos fazem em casa, via internet (e-mail) ou impressas (para os estudantes que não tinham internet em casa) e os professores, poderiam receber os materiais via site, e-mail, WhatsApp ou de maneira impressa. Além disso, estudantes e docentes poderiam acessar uma plataforma digital para acessarem os PETs e aulas gravadas sobre os conteúdos que foram transmitidas pela Rede Minas.

No Brasil, desde a segunda quinzena do mês de março de 2020, medidas como as políticas de isolamento social para o combate ao contágio do coronavírus ou Covid-19 afetaram drasticamente o cotidiano da população, além de impactar os setores da economia, política, relações sociais, cultura, relação com a cidade e com o espaço público. Segundo Marcia Gorett Grossi, Dalva Minoda e Renata Fonseca (2020) mais de 1,5 bilhão de estudantes de 165 países foram prejudicados pelo fechamento das escolas (medida tomada para frear a proliferação do vírus) por causa do contexto pandêmico.

No que diz respeito à pauta específica da educação, observamos que alguns governos, como o de Minas Gerais, por exemplo, com o intuito de amenizar os impactos causados pelo Covid-19, implantou o Ensino Remoto à Distância em todas as etapas da educação básica. Esse processo ocorreu de maneira emergencial, e foi preciso enfrentar o fato de que muitos alunos e professores tem dificuldade de acesso à internet e muitos deles não possuem aparelhos adequados para o acompanhamento de aulas e atividades virtuais.

Ao darmos início a uma pesquisa sobre o clima escolar de uma escola do Ensino Médio da Rede Estadual de Ensino em Cajuri-MG, as aulas foram suspensas no mês de março de 2020, por tempo indeterminado e a Secretaria de Estado de Educação de Minas Gerais (SEE/MG) elaborou o Regime de Estudo Não Presencial. Para tanto, foi ofertado aos estudantes um Plano de Estudos Tutorado (PET), organizado de acordo com o Currículo Referência de Minas Gerais e com o Plano de Curso da unidade de ensino com atividades não presenciais que os alunos fazem em casa, via internet (e-mail) ou impressas (para os estudantes que não tinham internet em casa) e os professores, poderiam receber os materiais via site, e-mail, WhatsApp ou de maneira impressa. Além disso, estudantes e docentes poderiam acessar uma plataforma digital para acessarem os PETs e aulas gravadas sobre os conteúdos que foram transmitidas pela Rede Minas.

\footnotetext{
${ }^{2}$ O Plano de Estudos Tutorado (PET) consiste em um instrumento de aprendizagem que visa permitir ao estudante, mesmo fora da escola, resolver questões e atividades escolares programadas, de forma autoinstrucional, buscar informações sobre os conhecimentos desenvolvidos nos diversos componentes curriculares, de forma tutorada e, possibilitar ainda, o registro e o cômputo da carga horária semanal de atividade escolar do estudante, em cada componente curricular.

${ }^{3}$ O Currículo Referência de Minas Gerais é um documento elaborado pela Secretaria de Estado de Educação de Minas Gerais (SEE/MG) e a União Nacional dos Dirigentes Municipais de Educação, seccional Minas Gerais (Undime-MG).Tem por objetivo oportunizar que todos os estudantes, independente da rede que eles estejam matriculados, tenham garantia e acesso à aprendizagem que está descrita no currículo formatado a partir da Base Nacional Comum Curricular (BNCC).

4 "O plano de unidade, ou unidade de ensino, é uma previsão mais específica e analítica do trabalho a ser desenvolvido durante um determinado período/tempo. Este plano procura reunir, num todo organizado, mais específico temas ou conteúdos listados, que se inter-relacionem e se complementem, compondo um conjunto mais facilmente compreensível, devido a sua significação" (Portal Educação, 2013).
} 


\section{Métodos e materiais}

Diante deste novo contexto, portanto, reformulamos a pesquisa e criamos três questionários muito similares para professores, alunos e funcionários, compostos por 4 questões abertas e 36 fechadas com escala Likert ${ }^{5}$ para os docentes, 37 para os estudantes e 31 para os funcionários. O questionário foi dividido em três partes: a primeira correspondia à identificação dos participantes, a segunda dizia respeito às relações construídas pelos participantes na escola e a última se referia ao contexto pandêmico (como se sentiam em estudar ou trabalhar neste período).

Os professores receberam o questionário através do Google Forms e os funcionários estavam trabalhando na escola presencialmente e receberam o questionário impresso, bem como o Termo de Consentimento Livre e Esclarecido - TCLE - e a carta de apresentação da pesquisa. O questionário impresso foi enviado aos estudantes no dia 30/09/2020 junto com o Plano de Estudos Tutorado (PET) e recolhidos no dia 26/10/2020 junto com o material de atividades escolares do PET. Além do Termo de Consentimento Livre e Esclarecido, foram enviados também Termos de Assentimento para que os responsáveis pelos participantes menores de 18 anos tivessem conhecimento da pesquisa e autorizassem ou não a participação dos estudantes .

Foram distribuídos 76 questionários para os 164 estudantes matriculados, para todos os 20 professores e todos os 5 funcionários da escola e obtivemos a devolução de 44 questionários dos estudantes ( 9 da Educação de Jovens e Adultos; 11 do $1^{\circ}$ ano, 13 do $2^{\circ}$ ano e 11 do $3^{\circ}$ ano do Ensino Médio), 7 dos docentes e de todos os 5 funcionários.

\section{Resultados e discussão}

\subsection{Os impactos do distanciamento social na percepção dos participantes}

Antes de trazer os dados obtidos na pesquisa, apresentamos o Construcionismo Social que foi a base teórica para a produção deste trabalho. O Construcionismo Social é uma perspectiva construída a partir dos anos de 1970 por diversos autores e autoras como Kenneth Gergen, Mary Gergen, Vivien Burr, Dian Marie Hosking, Lupicínio Îñiguez-Rueda, e no Brasil, podemos indicar alguns pesquisadores como Emerson Rasera, Carla Guanaes-Lorenzi, Marisa Japur e Mary Jane Paris Spink.

Segundo Rasera e Japur (2005), o construcionismo social surgiu alimentado por várias críticas aos modos tradicionais de fazer pesquisa que podem ser organizadas em três grandes grupos: a crítica social, a ideológica e retórico-literária. A crítica social emergiu diante da crítica da gênese social do pensamento científico por alguns autores como Marx, Weber, Scheler e Karl Mannheim; a crítica ideológica baseada na teoria crítica da Escola de Frankfurt-Horkheimer, Adorno, Marcuse, Benjamim e outros que criticam a ideia de neutralidade na ciência e, por fim, a crítica retórico-literária que analisa as metáforas dos textos científicos, compreendendo o mundo que são construídas.

\footnotetext{
${ }^{5} \mathrm{O}$ criador é o cientista social estadunidense Rensis Likert. É um tipo de escala para questionários usados para medir opiniões com um nível maior de nuance que uma simples pergunta de "sim" ou "não". A escala é usada em uma pergunta fechada quando os participantes têm opções de respostas pré-preenchidas. Normalmente, a pergunta de pesquisa da escala Likert de satisfação inclui uma opção moderada ou neutra, não apenas a resposta binária "sim ou não", como por exemplo: sim; em geral, sim; talvez; em geral, não ou não. Esse método permite descobrir graus de opinião que podem fazer a diferença para entender o feedback recebido (Surveymonkey, 1999).
} 
O movimento construcionista foca nos processos cotidianos, ou seja, como as pessoas constroem o mundo em que vivem através da linguagem e das relações entre elas. Essa perspectiva parte do pressuposto que tudo é uma construção social, tudo que existe recebe um significado que é construído entre as pessoas. O que somos/ estamos é o resultado das nossas relações sociais, ou seja, as afetações estão no "entre" e no "com" das relações sociais.

A perspectiva construcionista pode oferecer contribuições significativas para compreender as multiplicidades no âmbito escolar (Gergen \& Gergen, 2010), uma vez que pode nos auxiliar a compreender as relações que constroem e caracterizam este espaço. Nesse sentido, acreditamos que as relações sociais são essenciais na construção do processo de ensino-aprendizagem e na execução dos objetivos da escola. Dessa forma, como as relações foram afetadas por causa da pandemia, consequentemente, o processo de ensino-aprendizagem também foi profundamente alterado e nos propusemos a entender, do ponto de vista de todos os participantes da escola, como eles percebiam estas alterações e como isso afetava o seu processo de ensino-aprendizagem no caso de professores e estudantes e o trabalho, no caso dos funcionários.

A análise das informações foi realizada em quatro etapas: as respostas dos estudantes, dos docentes, funcionários e, por fim, a exploração de todos os dados a partir das lentes construcionistas. Inicialmente, foi realizada uma leitura flutuante do conteúdo, ou seja, um primeiro contato com os questionários que foram submetidos à análise.

\subsubsection{Percepções dos estudantes do Ensino Médio sobre a escola e os estudos}

Dos 44 estudantes, 22 eram alunas e 22 alunos. Sendo assim, embora a questão de gênero não fosse um foco da pesquisa, em alguns momentos, quando percebemos uma discrepância na resposta de alunos e alunas, apresentamos esta observação, quando as respostas são próximas em ambos os grupos, não nos detivemos em detalhar o que alunos e alunas responderam. Os discentes apresentaram faixa etária entre 15 e 55 anos, conforme o gráfico abaixo. Dos 27 estudantes de EJA da escola, 9 responderam ao questionário e eles tinham idade entre 18 e 54 anos. Quanto aos estudantes do Ensino Médio regular, as idades variaram entre 15 e 19 anos.

Uma das primeiras perguntas, após perguntamos dados de identificação dos estudantes, era se eles consideravam que eles tinham condições adequadas para estudar em casa, 19 assinalaram "com certeza"; 8 disseram "em geral, sim"; 14, "às vezes" e 3 responderam "não". Nos chamou a atenção que, apesar dos desafios de se estudar num espaço que não seja exclusivo pra isso como a sala de aula, não parece que os estudantes considerem que as condições de estudo que eles têm em casa sejam muito ruins. De qualquer forma, seria bom investigar aqueles fatores que podem estar dificultando o estudo dos estudantes, pois isso pode ser um complicador para seus resultados escolares. Em alguns casos, a escola pode conversar com os pais e tentar encontrar um caminho pra ajudar os estudantes a terem melhores condições para estudar, ainda que no espaço doméstico. 
Gráfico 1. Faixa etária dos estudantes

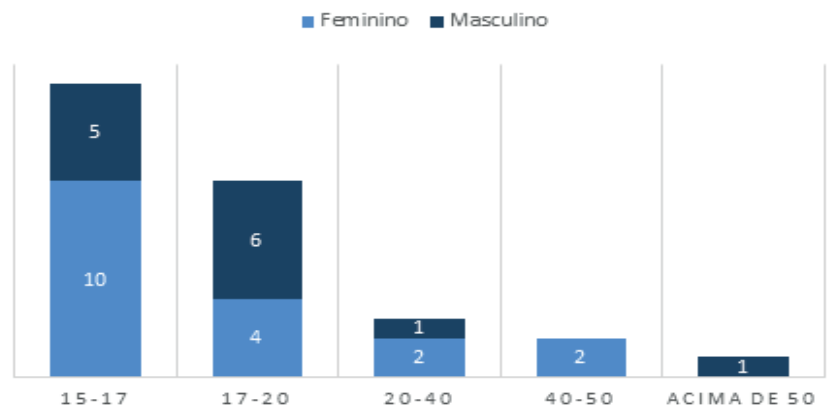

Fonte: Elaborado pela autora, 2020.

O período remoto (mediado por tecnologias digitais da informação e da comunicação) tem sido uma alternativa para os estudantes não ficarem afastados do processo de ensino-aprendizagem, no entanto há diversas implicações neste novo modelo adotado, como, por exemplo, a dificuldade de alunos e professores de acessarem a internet e a falta de aparelhos adequados para o acompanhamento das aulas.

Na pandemia, grande parte das escolas e das universidades estão fazendo o possível para garantir o uso das ferramentas digitais, mas sem terem o tempo hábil para testá-las ou capacitar o corpo docente e técnico-administrativo para utilizá-las corretamente. Há ainda outros obstáculos graves, especialmente para alunos e professores mais empobrecidos, muitos deles localizados na periferia das grandes cidades ou na zona rural. Faltam computadores, aparelhos de telefonia móvel, software e Internet de boa qualidade, recursos imprescindíveis para um EaD que resulte em aprendizagem. Não podemos esquecer que saúde física e saúde mental andam juntas. A duração prolongada do confinamento, a falta de contato pessoal com os colegas de classe, o medo de ser infectado, a falta de espaço em casa - torna o estudante menos ativo fisicamente do que se estivesse na escola - , e a falta de merenda para os alunos menos privilegiados são fatores de estresse que atingem a saúde mental de boa parte dos estudantes da Educação Básica e das suas famílias (Dias \& Pinto, 2020, p. 546).

Como a internet é um recurso hoje fundamental para os estudos e a comunicação, outra pergunta foi sobre como os estudantes percebiam a internet que tinham em casa.

Tabela 1. Internet dos estudantes

\begin{tabular}{lccc}
\hline & F & M & Total \\
\hline Ótima & 1 & 9 & 10 \\
Boa & 4 & 5 & 9 \\
Razoável & 12 & 5 & 17 \\
Ruim & 2 & 2 & 4 \\
Não tenho & 3 & & 3 \\
Não respondeu & & 1 & 1 \\
\hline
\end{tabular}

Fonte: Elaborado pela autora, 2020. 
Os dados mostram a diversidade de acesso dos estudantes, embora a maioria afirme ter uma internet ótima, boa ou razoável, há 3 estudantes sem internet em casa e é fundamental que a escola tenha esta clareza para evitar exclusões quando se trata de acesso aos conteúdos e atividades escolares. Além da internet, o tipo de aparelho utilizado para acessá-la pode facilitar ou dificultar o uso de alguns recursos e nem sempre este aparelho é de uso exclusivo do estudante e ele/a precisa conciliar seu uso com outros familiares.

Para compreender melhor esta situação, perguntamos aos estudantes que recursos eles utilizavam pra estudar e mais de uma resposta podia ser marcada. As respostas aprofundam um pouco mais sobre os limites do acesso dos estudantes: 1 menina não respondeu a questão, 1 menino disse que não tem nenhum dos aparelhos indicados (o mesmo que assinalou na questão anterior não ter acesso à internet) e nenhum dos estudantes disse usar tablet. 21 alunos e 21 alunas usam celular, 1 menina e 3 alunos disseram usar notebook e 4 alunos assinalaram usar computador de mesa. Aqui fica bem clara a diferença entre os sexos já que apenas 1 menina usa notebook, todas as demais usam celular, enquanto 3 alunos utilizam notebook e 4 computador de mesa.

Os dados mostram que os alunos relataram ter mais aparelhos disponíveis do que as alunas e com aparelhos com tela e teclado maiores, que facilitam bastante a leitura e escrita de um texto, bem como a resolução de exercícios. É bem importante pensar nisso para planejar o tipo de atividade a ser realizado pelos estudantes e também para saber se alguns estudantes terão mais dificuldades na realização das tarefas a eles destinadas. Além disso, quando um destes aparelhos apresenta algum problema, ele pode não ter outro pra realizar a tarefa da escola e também pode não ter sempre os aparelhos disponíveis para a realização de trabalhos escolares. Para identificar isso, perguntamos com quantas pessoas os estudantes compartilhavam os aparelhos.

Tabela 2. Compartilhamento dos aparelhos de acesso à internet

\begin{tabular}{lccc}
\hline & $F$ & $M$ & Total \\
\hline Só eu utilizo & 12 & 11 & 23 \\
1 pessoa & 1 & 2 & 3 \\
2 pessoas & 4 & 3 & 7 \\
3 pessoas & 2 & 3 & 5 \\
4 ou mais pessoas & 3 & 3 & 6 \\
\hline
\end{tabular}

Fonte: Elaborado pela autora, 2020.

Na questão anterior, 21 alunas e 21 alunos disseram usar celular, mas nesta questão apenas 12 alunas e 11 alunos afirmaram que eles são os únicos a usarem o aparelho, o que nos leva a pensar que o celular pode não ser do estudante, mas emprestado ou compartilhado com outra pessoa. Quanto maior o compartilhamento, mais difícil é para o estudante realizar a atividade. É provável que ele/a tenha que negociar e ter um tempo limitado, já que outras pessoas dependem do mesmo aparelho. 
Não dá pra avaliar em que medida isto é um fator complicador ou não dos estudos, de qualquer forma, é bem significativo que, sendo o celular o principal recurso usado pelos estudantes, 10 alunas e 11 alunos compartilhem os aparelhos com mais pessoas.

$\mathrm{Na}$ escola investigada, as aulas foram suspensas no mês de março de 2020, por tempo indeterminado, e a Secretaria de Estado de Educação de Minas Gerais (SEE/MG) elaborou o Regime Especial de Atividades Não Presenciais (REANP). Para tanto, foi ofertado aos estudantes um Plano de Estudos Tutorado (PET), organizado de acordo com o Currículo Referência de Minas Gerais ${ }^{6}$ e com o Plano de Curso da unidade de ensino ${ }^{7}$, com atividades não presenciais que os alunos faziam em casa, via internet (e-mail) ou impressas (para os estudantes que não tinham internet em casa), e os professores poderiam receber os materiais via site, e-mail, WhatsApp ou de maneira impressa. Além disso, estudantes e docentes poderiam acessar uma plataforma digital para acessarem os PETs e aulas gravadas sobre os conteúdos que foram transmitidas pela Rede Minas ${ }^{8}$.

O Plano de Estudos Tutorado (PET) consiste em um instrumento de aprendizagem que visa permitir ao estudante, mesmo fora da escola, resolver questões e atividades escolares programadas, de forma autoinstrucional, buscar informações sobre os conhecimentos desenvolvidos nos diversos componentes curriculares, de forma tutorada e, possibilitar ainda, o registro e o cômputo da carga horária semanal de atividade escolar vivida pelo estudante, em cada componente curricular (Projeto Político Pedagógico, 2020, p. 39).

O período remoto (mediado por tecnologias digitais da informação e da comunicação) tem sido uma alternativa para os estudantes não ficarem afastados do processo de ensino-aprendizagem, no entanto há diversas implicações deste novo modelo adotado, como, por exemplo, a dificuldade de alunos e professores de acessarem a internet e a falta de aparelhos adequados para o acompanhamento das aulas.

Perguntamos ainda como os estudantes percebiam o fato de estudar em casa durante a pandemia e 1 menina e 5 alunos assinalaram que consideravam que: "é melhor do que estudar na escola"; 1 menina e 3 alunos marcaram "é o mesmo que estudar na escola", mas 20 alunas e 14 alunos indicaram que estudar em cada "é pior do que estudar na escola". Claramente, depois de 4 meses estudando em casa, 34 dos 44 estudantes compreendiam que a escola é o melhor lugar para estudar, mas seria bem interessante entender porque alguns, especialmente os alunos, não viam diferença entre estudar em casa ou na escola e 5 alunos e 1 aluna considerava que era melhor estudar em casa que na sua escola.

Aprofundando mais esta questão, perguntamos se as atividades à distância ensinavam "mais", "o mesmo" ou "menos" que as aulas presenciais. Agora 36 dos 44 participantes (20 alunas e 16 alunos) indicaram que ensinavam "menos", 1 aluna e 3

\footnotetext{
${ }^{6}$ O Currículo Referência de Minas Gerais é um documento elaborado pela Secretaria de Estado de Educação de Minas Gerais (SEE/MG) e a União Nacional dos Dirigentes Municipais de Educação, seccional Minas Gerais (Undime-MG). Tem por objetivo oportunizar que todos os estudantes, independentemente da rede em que eles estejam matriculados, tenham garantia e acesso à aprendizagem que está descrita no currículo formatado a partir da Base Nacional Comum Curricular (BNCC).

${ }^{7}$ O plano de unidade, ou unidade de ensino, é uma previsão mais específica e analítica do trabalho a ser desenvolvido durante um determinado período/tempo. Este plano procura reunir, num todo organizado, mais específico temas ou conteúdos listados, que se inter-relacionem e se complementem, compondo um conjunto mais facilmente compreensível, devido a sua significação" (Portal Educação, 2020).

${ }^{8}$ TV pública educativa que sintetiza a diversidade social e cultural mineira.
} 
alunos marcaram a opção "o mesmo que as aulas presenciais" e 1 menina e 3 alunos consideravam que as atividades à distância ensinavam "mais" que as presenciais. Comparando com as respostas anteriores, ainda que 1 menina e 5 alunos afirmaram que estudar em casa "é melhor do que estudar na escola", em relação ao aprendizado, agora 1 aluna e 3 alunos afirmaram que aprendiam mais com as atividades à distância. Ou seja, mesmo os poucos que achavam melhor estudar em casa não foram unânimes em afirmar que as atividades à distância ensinam mais.

Tabela 3. Alunos estudando durante a pandemia

\begin{tabular}{lccc}
\hline & $F$ & $M$ & Total \\
\hline Mais do que antes & 1 & 4 & 5 \\
O mesmo que antes & 3 & 3 & 6 \\
Menos que antes & 18 & 15 & 33 \\
\hline
\end{tabular}

Fonte: Elaborado pela autora, 2020.

Além da percepção sobre a escola e as atividades realizadas, procuramos saber se os estudantes mantiveram ou alteraram o ritmo de estudos durante a pandemia. 1 menina e 4 alunos assinalaram que passaram a estudar "mais do que antes", 3 alunas e 3 alunos disseram "o mesmo que antes", mas 18 alunas e 15 alunos reconheceram que, durante a pandemia, estudavam "menos que antes". Estando estes estudantes no final da vida escolar obrigatória e muitos deles certamente pretendendo realizar o Exame Nacional do Ensino Médio - ENEM - e iniciar um curso superior, é provável que a necessidade de manter os estudos no ambiente doméstico tenha prejudicado a qualidade da aprendizagem destes estudantes. Vários são os fatores intervenientes neste processo: a dificuldade de acesso à internet, o compartilhamento de aparelhos, o fato de o ambiente doméstico ter muito mais elementos distratores, a necessidade de organização de um horário definido de estudo, conciliar atividades cotidianas com as escolares, bem como desenvolver autonomia pela própria aprendizagem.

Nas atividades remotas de ensino, o estudante fica fisicamente longe do docente, fazendo com que o discente se torne o principal responsável pelo processo de ensino e de aprendizagem. Há professores que não estão capacitados para lecionar à distância e não sabem lidar com as novas tecnologias, que para Dias e Pinto (2020), o ensino através da internet "não pode ser a única solução, esta metodologia tende a exacerbar as desigualdades já existentes, que são parcialmente niveladas nos ambientes escolares, simplesmente, porque nem todos possuem o equipamento necessário" (Dias \& Pinto, 2020, p. 546).

Em uma das questões abertas, perguntamos aos estudantes se eles estavam sentindo falta da escola e pedíamos que justificassem sua resposta, numa questão aberta. Os alunos que sentem muito a falta da escola justificam (quadro 1.0) sua resposta devido à falta de interação com os colegas e das explicações dos professores, uma vez que o estudo remoto, na pandemia, ocasionou o afastamento social. Os alunos que responderam que em geral não ou não sentem falta da escola justificaram suas respostas por não gostarem da instituição, por sentirem desmotivados quando 
um professor privilegia um discente e outro não, pelo horário integral, quando não entendem o conteúdo e o docente não explica novamente e por não gostarem de algumas pessoas que compartilham o ambiente escolar.

Quadro 1. Justificativas dos estudantes por estarem ou não sentindo falta da escola durante a pandemia

\begin{tabular}{llc}
\hline \multicolumn{1}{c}{ Falta } & \multicolumn{1}{c}{ Respostas } & Número \\
\hline $\begin{array}{l}\text { Sentiam falta } \\
\text { da escola }\end{array}$ & Aprendem mais dentro da escola junto com os professores e colegas. & 18 \\
& Tiram as dúvidas com os professores. & 6 \\
& Relações com os colegas. & 9 \\
& Os professores não explicama matéria novamente quando o estudante & 1 \\
& está com dificuldade. & 1 \\
\hline $\begin{array}{l}\text { Não sentiam } \\
\text { falta da es- } \\
\text { cola }\end{array}$ & Não gosta do tempo integral. & 1 \\
& Não gosta das pessoas que estão na escola. & 2 \\
\hline $\begin{array}{l}\text { Não respon- } \\
\text { deram }\end{array}$ & Os professores não gostam de todos os alunos. & 1 \\
\hline Fonte: Elaborado pela autora, 2020. & 5
\end{tabular}

Chama atenção que uma das respostas foi o estudante não gostar do período integral, já que, obrigatoriamente, todos os estudantes foram incluídos no tempo integral, sendo esta a única escola da cidade a oferecer ensino médio. Caso os estudantes não quisessem ficar no tempo integral, teriam que abandonar o ensino médio ou ir estudar em outra cidade. Devido à pandemia, houve apenas 17 dias letivos e, em 17 de março de 2020, as aulas presenciais foram suspensas. Assim, os estudantes tiveram pouquíssima oportunidade de experimentar o tempo integral, que estava sendo implementado pela primeira vez na escola. As respostas abertas enfatizam que os estudantes consideram que aprendem mais na escola, podem tirar as dúvidas com os professores e também sentem falta da relação com os colegas. De acordo com o Construcionismo Social, somos seres relacionais, coletivos e não individuais.

Como produtos e produtores de uma construção coletiva, cada relação em que participamos, cada contato que temos nos altera e altera os demais, influenciando a nossa constituição psíquica e o ambiente à nossa volta. As novas tecnologias, especialmente as TIC's, tecnologias de informação e comunicação, provocaram uma revolução na nossa forma de relacionar com o mundo e com as pessoas, pois elas aproximam diferentes e variados contextos culturais e nos transformam profundamente, já que somos, precisamente, este conjunto de relações (Souza, 2020, p.3).

Além disso, consideramos que o aprendizado é relacional, mesmo que seja feito com base um livro, um aplicativo, um exercício, um vídeo. Há pessoas que elaboraram estes materiais e que podem não estar presencialmente ali. Ainda assim, são bem diferentes as relações feitas face a face e as remotas. Especialmente durante a pandemia, as tecnologias de informação e comunicação favoreceram a conectividade entre as pessoas "encurtando" o afastamento e o distanciamento entre elas. Essa conexão virtual, por sua vez, reduz o impacto psicológico do isolamento social e pro- 
porciona uma nova maneira para as pessoas se relacionarem. No entanto, como na escola, os estudantes não tem acesso à internet, não havia sequer a possibilidade de reuniões virtuais com os colegas de sala e os professores e, para os estudantes, este afastamento tornava o aprendizado mais difícil. Por outro lado, é preciso considerar que nem sempre estas relações são amistosas e pelo menos 4 das respostas abertas dos estudantes foram de que não sentiam falta da escola porque sentiam que os professores discriminavam alguns estudantes ou que não tinham boas relações com os colegas.

É preciso estar atento a estes estudantes que não se sentem bem na escola porque, além de poderem ter prejuízos nos seus resultados escolares, é muito comum que desenvolvam baixa autoestima, dificuldades de relacionamento que podem perdurar por muitos anos em suas vidas, como consequências de relações que poderiam ter sido melhor trabalhadas no espaço escolar.

Considerando que o ambiente escolar é composto por todos os seus membros, visamos conhecer como os professores e funcionários estavam lidando com este novo contexto. Como dissemos acima, as perguntas de todos os questionários eram muito similares, mas adaptadas à cada categoria. Como pudemos ver, boa parte dos estudantes dizia sentir falta da escola e que aprendiam melhor nas aulas presenciais, mas houve também os que se sentiam melhor estudando em casa e até considerando que aprendiam melhor do que na escola. Como os professores estavam vivenciando esta situação tão nova e inusitada é o que vamos abordar agora.

\subsubsection{A percepção dos docentes e funcionários do Ensino Médio sobre a escola e a educação durante a pandemia}

\section{Docentes}

Como os docentes preencheram o questionário no mês de junho e estavam deste março trabalhando de forma remota, suas respostas se referem a este período de 3 meses desta nova experiência. Dos 20 professores da escola, 7 responderam o questionário, sendo 4 mulheres e 3 homens. Mostramos, a seguir, a formação destes professores e o ano em que terminaram a graduação.

Tabela 4. Formação dos professores

\begin{tabular}{|c|c|c|c|}
\hline \multicolumn{2}{|c|}{$\mathrm{F}$} & \multicolumn{2}{|c|}{ M } \\
\hline Ano de conclusão & Graduação & Ano de conclusão & Graduação \\
\hline 2000 & $\begin{array}{l}\text { Pedagogia e Edu- } \\
\text { cação Artística }\end{array}$ & 2002 & Matemática \\
\hline 2008 & Filosofia & 2011 & História \\
\hline 2009 & Pedagogia & 2019 & Geografia \\
\hline 1998 & Zootecnia & & \\
\hline
\end{tabular}

Fonte: Elaborado pela autora, 2020.

Perguntados se eles tinham condições adequadas para trabalhar em casa, 1 professora assinalou "com certeza"; 4 docentes disseram "em geral, sim", 1 professor, "às vezes" 1 professora afirmou que "em geral, não". Assim como os estudantes, apesar do desafio de se trabalhar em casa, de acordo com as respostas, não parece que os 
educadores considerem que estas condições sejam muito ruins. De qualquer forma, é válido investigar os fatores que podem estar dificultando o trabalho dos professores, pois isso pode ser um complicador para seus resultados e podemos supor que o trabalho doméstico, o cuidado com os filhos, muito mais associado ao sexo feminino na nossa sociedade possa ter levada à professora a considerar que, em geral, não tem boas condições de trabalho em casa, mas isso não foi possível investigar com o questionário utilizado. Assim como com os estudantes, seria importante se pensar em maneiras de se melhorar estas condições de trabalho doméstico, caso seja possível.

Embora os estudantes não tivessem atividades de estudo online, para os professores o acesso à internet pode melhorar o trabalho, facilitando o acesso a materiais de estudo, a comunicação com colegas, com a gestão da escola e também com os estudantes. Sobre a internet que tinham em casa, 1 professor respondeu "ótima", 2 "boa", 3 "razoável" e 1 "ruim". A dificuldade de acesso à internet é um fator que interfere no desempenho do trabalho remoto dos docentes, que deve ser levado em consideração pela instituição.

Neste período de distanciamento social, a internet trouxe alguns benefícios como manter as relações entre as pessoas, relacionamentos afetivos, entretenimentos e conhecer a diversidade cultural que já vinham ocorrendo nos últimos anos através das telas de celulares e computadores. E devido ao surgimento do Covid-19, potencializou seu uso para conseguir manter certas rotinas durante a pandemia e, também, as relações entre as pessoas. A sociabilidade digital é essencial no contexto pandêmico e a contemporaneidade, ainda que sofra constantes mutações com a incorporação de novas tecnologias, pois elas são capazes de (re)estabecer as relações. Temos a noção de que muitas pessoas não têm acesso a internet e políticas públicas devem ser feitas para solucionar este problema, pois a educação digital ainda é um desafio, tanto para os educadores quanto para os estudantes.

Sobre o uso de aparelhos, 3 docentes assinalaram utilizar "computador de mesa", 5 "notebook" e 6 também usam celulares. Nenhum professor usa exclusivamente o celular para as atividades de trabalho. Sobre o compartilhamento dos aparelhos, 4 docentes afirmaram que apenas eles utilizavam o(s) aparelho(s) e 3 compartilhavam com mais uma pessoa, o que pode fazer com que estes tenham mais dificuldades na realização das suas atividades de trabalho. Destacamos também que, dos 20 professores da escola, 13 não responderam ao questionário e podemos levantar hipóteses de dificuldade de acesso à internet, de aparelho disponível e mesmo falta de familiaridade com atividades digitais, mas não sabemos se foram estes os motivos pelos quais os demais professores não participaram.

Sobre como estavam percebendo o trabalho em casa durante a pandemia, 2 professores responderam que trabalhavam "mais do que antes" e 5 "menos do que antes". Não sabemos se o fato de terem menos contato com os estudantes, de estarem fazendo suas atividades no conforto de suas casas levaram os professores a considerar que tinham menos trabalho. Devemos considerar ainda que, da forma como foram estruturados os Planos de Ensino Tutorados, as atividades já vinham prontas para os estudantes e bastava aos professores corrigirem os exercícios definidos pelas apostilas. 
Perguntamos aos professores se eles consideravam que as atividades à distância ensinavam "mais", "o mesmo" ou "menos" que as aulas presenciais e todos responderam que ensinavam menos do que as aulas presenciais, coincidindo com a resposta de 36 estudantes, embora 8 estudantes partiam do princípio que estavam aprendendo mais com o ensino remoto. Não sabemos se esta percepção dos professores se devia aos resultados que eles estavam percebendo nos exercícios enviados pelos estudantes ou se era apenas uma opinião, considerando que talvez os estudantes não tivessem a mesma dedicação de tempo ao estudar em casa, já que não tinham aulas presenciais.

Será que os professores sentiam falta da escola? A esta pergunta, todos docentes responderam que estão sentindo falta da escola. Eles justificaram essa resposta da seguinte maneira: "o ambiente escolar é acolhedor, faz muita falta o contato direto com as pessoas"; "além da rotina de sair de casa para exercer uma atividade, os relacionamentos são agradáveis e fazem falta"; "sinto falta dos alunos e alunas"; "o clima na escola é muito agradável". Identificamos que os professores também sentem falta das relações sociais com as pessoas que integram a escola. Para o construcionismo, a realidade é construída socialmente por meio da cultura, dos valores e da história de cada sujeito, pois somos seres relacionais e através das nossas relações que os conhecimentos são construídos e sustentados (Gergen \& Gergen, 2010). Assim, entendemos o quão as relações são importantes para construir a escola.

\section{Funcionários}

Todos os 5 funcionários de serviços gerais da escola se dispuseram a participar da pesquisa e, embora estes não tenham relação direta com as atividades de ensinoaprendizagem, entendemos que sua opinião também seria muito importante para entender como eles percebiam a escola e o ensino nela oferecido, antes e durante a pandemia. Eles responderam o questionário impresso, pois estavam trabalhando na escola, apesar da pandemia. Dos 5 funcionários que participaram desta pesquisa, 4 são do sexo feminino e 1 masculino e todos eram auxiliares de serviços gerais.

Gráfico 2. Tempo de trabalho dos funcionários nesta instituição escolar

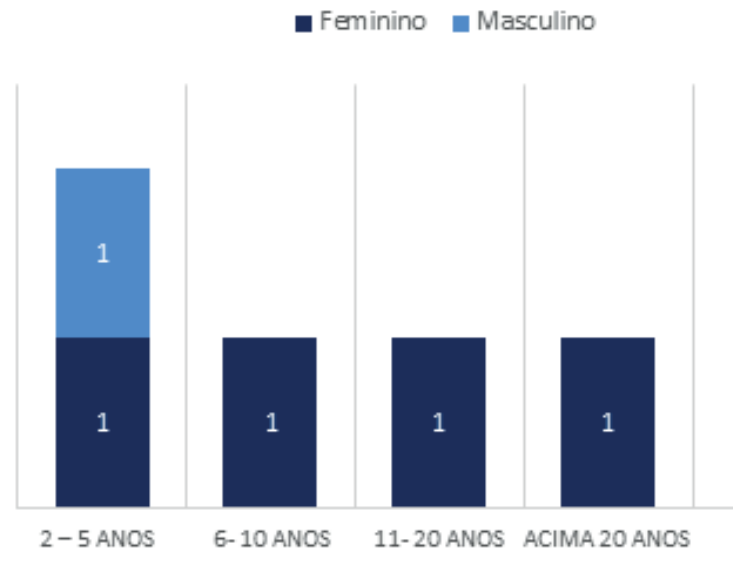

Fonte: Elaborado pela autora, 2020. 
Como podemos ver, os funcionários têm um bom tempo de trabalho na instituição e, portanto, um bom conhecimento dela e de seu funcionamento.

Devido à pandemia, os funcionários também tiveram modificações em suas jornadas de trabalho e 4 deles responderam que, durante a pandemia, trabalhavam "menos do que antes" e 1 funcionária não respondeu. Provavelmente a ausência de pessoas circulando pela instituição diminuiu a necessidade de limpeza dos espaços, além de não haver mais a necessidade de fazer a merenda escolar, lembrando que todos eles eram funcionários de serviços gerais.

$\mathrm{Na}$ oportunidade, também perguntamos se eles estavam sentindo falta dos estudantes na escola e todos responderam "muito" e optamos por transcrever todas as respostas abertas desta questão porque elas dizem muito do sentimento dos funcionários: "Escola sem alunos, é escola sem vida. A alegria de todos na escola é vê-la com alunos."; "Os alunos são a base de tudo."; "Sem nossos alunos a escola não tem vida. Aqui sem eles não tem alegria. O agitamento do dia a dia é muito bom com eles na escola."; "Porque sem eles o colégio fica muito vazio."; "Eu gosto da escola quando os alunos estão aqui.". Destacamos estas respostas porque apesar de evidenciarem estar trabalhando menos, os funcionários deram a entender que preferiam a convivência, a agitação que traziam vida e alegria à instituição. Acreditamos que as relações sociais exercem forte influência nas transformações da sociedade e que as relações no ambiente da educação são fundamentais para reforçar o senso de coletividade e pertencimento.

\section{Considerações finais}

No início de 2020, poucos poderiam imaginar que passaríamos todo o ano em situação de distanciamento social e nem o governo, as escolas, as famílias ou os estudantes tiveram tempo de se preparar pra um ensino remoto que traz muitas mudanças para todos os envolvidos, demandando uma adaptação radical de todos, algo que demanda tempo, reflexão, organização e reajuste constante.

Neste sentido, consideramos que é fundamental compreender melhor como as pessoas lidaram com este novo contexto, e, em se tratando de educação escolar, ainda mais no ensino médio, última etapa de educação escolar obrigatória no Brasil, será difícil avaliar os impactos do distanciamento social, do ensino remoto para a aprendizagem e formação dos estudantes. Nossa pesquisa teve por objetivo ouvir alguns protagonistas deste cenário e, ainda com as dificuldades da pandemia, já que tivemos que fazer a pesquisa através de um questionário e sem contato direto com os participantes, consideramos que obtivemos dados importantes sobre como aqueles estudantes, professores e funcionários percebiam a escola e o ensino durante o período de distanciamento.

Nem sempre é possível prever e planejar, antecipadamente, situações como o mundo teve que enfrentar em 2020, levando os sistemas de ensino a terem que se reinventarem rapidamente visando minimizar as consequências da falta de aulas presenciais. Considerando que somos seres relacionais e extremamente dependentes uns dos outros para o nosso desenvolvimento e aprendizagem, é possível que este distanciamento tenha afetado muito as crianças, adolescentes e jovens que tem na escola, frequentemente, seu principal espaço de socialização, integração e 
aprendizagem formal. Portanto, ouvi-los pode nos ajudar a, no decorrer do processo, fazer ajustes visando manter a qualidade do ensino, a motivação e compromisso dos estudantes com as atividades escolares e a integração entre as pessoas, de maneira segura e condizente com a realidade de cada um. Esta também foi uma oportunidade para se repensar a instituição escolar. Afinal, a escola é ou não importante? O quanto se aprende dentro ou fora da sala de aula?

Parece-nos, que nesse contexto de pandemia, os participantes da pesquisa passaram a valorizar e compreender a importâncias das relações, sobretudo na escola. Os estudantes abordaram a falta de interação com os colegas e professores; os docentes também falaram sobre a falta do contato direto com as pessoas e sentiram muito a falta dos alunos; e os funcionários também falaram sobre o vazio que eles sentiam na escola sem os alunos.

Pelo menos na percepção dos estudantes e professores da escola pesquisada o espaço escolar, a integração entre educadores e educandos estava sendo percebida como potencializadora da aprendizagem e professores e estudantes consideravam que o aprendizado tinha sido prejudicado com o ensino remoto. Será que aulas online com todos os estudantes tendo acesso à internet e podendo estar juntos em atividades síncronas melhorariam esta percepção? O que é necessário fazer para melhorar o ensino e a qualidade de vida, de trabalho, de ensino e aprendizagem das pessoas envolvidas em contextos formais de aprendizagem? Não temos pretensão de dar respostas a estas perguntas, mas consideramos que ouvir os envolvidos no contexto escolar pode auxiliar, cada escola, dentro das suas condições específicas, a buscar melhores formas de ensino e aprendizagem, buscando não apenas manter a qualidade do ensino e da aprendizagem, mas também de promover a saúde física e mental de seus integrantes que, embora estejam fora do espaço físico da instituição, a ela pertencem e, muitas vezes, dela dependem para se apropriarem de conteúdos básicos para a vida social e cultural da sociedade atual.

\section{Referências}

De Souza, R. (2020). Uma análise construcionista social da liberdade na educação. Periódico Horizontes, 38(1), Disponível em https://bit.ly/3kGxGDN.

Dias, É. \& Pinto, F. (2020). A Educação e a Covid-19. Ensaio: Avaliação e Políticas Públicas em Educação, 28(108), 545-554. Disponível em https://bit.ly/3rkrSBk.

Gergen, K. J. \& Gergen, M. (2010). Construcionismo social: um convite ao diálogo. Rio de Janeiro: Instituto Noos.

Guanaes, C. \& Japur, M. (2008). Contribuições da poética social à pesquisa em psicoterapia de grupo. Estudos de Psicologia, 13(2), 117-124. Disponível em: https://www.scielo.br/pdf/ epsic/v13n2/03.pdf.

Portal Educação (2020). Plano de Unidade de Ensino. Disponível em https://bit.ly/3xV215c .

Rasera, E. F. \& Japur, M. (2005). Os sentidos da construção social: o convite construcionista para a Psicologia. Paidéia, 15(30), 21-29. Disponível em https://bit.ly/3hTqClE.

Surveymonkey (1999). Saiba quando e como usar perguntas de pesquisa com escala Likert. Disponível em https://bit.ly/360j9xW.

Como citar em APA:

Celestino, S. M. y De Souza R. (2021). Relações sociais, pandemia da Covid-19 e ensino médio. Revista Ibero-americana de Educação, 86(2), 45-59. https://doi.org/10.35362/rie8624188 